\title{
Factors Associated With Stillbirth Among Pregnant Women in Nepal
}

\author{
Mahesh Bhusal', Nirmal Gautam², Apiradee Lim', Phattrawan Tongkumchum ${ }^{1}$ \\ ${ }^{1}$ Department of Mathematics and Computer Science, Faculty of Science and Technology, Prince of Songkla University, Pattani, Thailand; \\ ${ }^{2}$ Department of Public Health, Karnali College of Health Science, Kathmandu, Nepal
}

Objectives: Stillbirth is a common adverse pregnancy outcome that represents a distressing and traumatic event for women and their partners. The aim of this study was to identify factors associated with stillbirth in ever-pregnant women in Nepal.

Methods: This study utilized the individual women's dataset from the Nepal Demographic and Health Survey, conducted in 2016. The dependent variable of interest was whether women had at least 1 stillbirth during their lifetime. The associations between independent variables and the dependent variable of the study were analyzed using a multiple logistic regression model.

Results: Among 8918 ever-pregnant women aged 15-49 years, 488 had experienced at least 1 stillbirth during their lifetime, representing $5.5 \%$ of the total. After adjusting each factor for the confounding effects of other factors, maternal age, maternal education, place of residence, and sub-region remained significantly associated with having experienced stillbirth.

Conclusions: Stillbirth continues to be a major problem among women, especially those with higher maternal age, those who are illiterate, and residents of certain geographical regions. To minimize stillbirth in Nepal, plans and policies should be focused on women with low education levels and residents of rural areas, especially in the western mountain and far-western hill regions.

Key words: Pregnancy, Stillbirth, Women, Nepal Demographic and Health Survey, Nepal

\section{INTRODUCTION}

Stillbirth is a common adverse outcome of pregnancy that contributes considerably to poor maternal health. Globally, each year, 2.65 million babies (birth weight $\geq 1000 \mathrm{~g}$ or $\geq 28$ weeks of gestation) are born dead [1]. It has been found that $98 \%$ of these deaths occurred in developing countries, primarily in low-resource settings. Worldwide, from 1995 to 2009, the

Received: November 25, 2018 Accepted: March 19, 2019

Corresponding author: Nirmal Gautam, MS

Department of Public Health, Karnali College of Health Science,

Gaushala, Kathmandu 44600, Nepal

E-mail: gautamnirma|@karnalicollege.edu.np

This is an Open Access article distributed under the terms of the Creative Commons Attribution Non-Commercial License (http://creativecommons.org/licenses/bync/4.0/) which permits unrestricted non-commercial use, distribution, and reproduction in any medium, provided the original work is properly cited. stillbirth rate declined by $14.0 \%$, representing a $1.1 \%$ decrease per year; however, this improvement mainly occurred in developed countries, rather than in developing countries [1,2]. In Nepal, the rate of stillbirth has been declining in recent years. It has been reported that the national rate of stillbirth was 18.0 per 1000 live births in 2015 [3]. There exist pronounced spatial variations in stillbirth in Nepal, and the stillbirth rate is as high as 35.4 per 1000 births in Sarlahi, a rural district of Nepal [4].

There are several common risk factors for stillbirth in developing and developed countries. Maternal age ( $>35$ years or $<20$ years), lack of education, socioeconomic characteristics, lack of antenatal care (ANC), history of stillbirth, hypertension, smoking, obesity, and diseases such as syphilis and malaria are some common factors contributing to stillbirth $[5,6]$. There is a need for studies on stillbirth and related factors in developing 
countries [7]. In these settings, recent efforts have been made to classify stillbirth by the sign of maceration, with a distinction between ante-partum (death of babies occurring more than 12 hours before delivery) and intra-partum (death occurring less than 12 hours before delivery) stillbirth. The rate of ante-partum stillbirth is influenced by maternal health and the quality of ANC, whereas intra-partum stillbirth is assumed to reflect the quality of obstetric and delivery care. In this setting, more than half of stillbirths may be intra-partum $[8,9]$.

Since stillbirths involve loss of life, they can be viewed as tragic. Furthermore, many parents face psychological effects after stillbirth, including anxiety and depression, post-traumatic stress disorder, and stigmatization [10]. In addition, women who have experienced stillbirth are more likely to experience it again in later pregnancies [11].

Controlling and preventing stillbirth is of great importance for achieving the target of 12 or fewer stillbirths per 1000 births in every country by 2035, as proposed by Global Every Newborn Action Plan by the 67th WHO Assembly [12]. Knowledge of the relative importance of the various factors affecting stillbirth in developing countries such as Nepal is lacking. Very few studies have been conducted, based on data from some districts and a few hospitals, but no study has been conducted based on national data on stillbirth in Nepal $[5,13]$. Obtaining basic data on the factors influencing stillbirth will facilitate the development of better public health interventions to reduce these preventable deaths and to improve maternal health. The objective of our study was therefore to explore various factors associated with stillbirth in ever-pregnant women in Nepal.

\section{METHODS}

This study analyzed data from the Nepal Demographic and Health Survey (NDHS) 2016, which is a national representative cross-sectional survey conducted every 5 years. The NDHS 2016 was based on multistage stratified cluster sampling with subjects sampled from villages and municipalities within 75 districts of Nepal. In the first stage, the probability-proportional-to-size-strategy was used to select the enumeration areas (EAs), which were wards in rural areas and sub-wards in urban areas. In the second stage, random sampling was used to select households from EAs. The 2016 survey interviewed 10826 households, including 12674 women aged 15-49 years. The details of data collection are available elsewhere [14]. Among 12674 women, 8918 women aged 15-49 years had experi- enced at least 1 pregnancy outcome during their lifetime. Thus 3756 women who had never been pregnant prior to the survey were excluded from the data analysis. Maternal age, maternal occupation, use of tobacco, maternal and paternal education, wealth index, cooking fuel, residence, and sub-regions were included as factors potentially associated with stillbirth. Women were categorized by age as: 15-24, 25-29, 30-39, and 40-49 years. Maternal occupation status was classified as: not working, agriculture, and others (e.g., professional/techni$\mathrm{cal} /$ managerial, clerical, sales and service, skilled/unskilled labor). Mothers who reported smoking cigarettes, pipes, or bidis or chewing/snuffing tobacco were classified as using tobacco. Maternal and paternal education status was classified as: no education, primary education, and secondary or higher education. Participants were classified by wealth status as: poor (poorest and poor), middle, and rich (richer and richest). Cooking fuel was classified as: relatively non-polluting (e.g., biogas, electricity, natural gases, liquefied petroleum gas [LPG]) and relatively polluting (e.g., kerosene, coal, ignites, charcoal, wood, straw, agricultural crops, animal dung). As mentioned above, participants were classified by the wealth index into 3 sub-groups: poor, middle, and rich. These 3 sub-groups were based on materials and goods consumed by the household, ranging from durable goods such as televisions, bicycles, and cars to housing-related characteristics, such as the presence of a source of drinking water, food, toilet facilities, and agricultural and flooring materials. Households in which sufficient supplies of food, water, hand-washing materials, agricultural crops and fields for production, and other consumer goods were present for only 6 months were classified as poor. Households in which those goods and supplies sufficed for 6-12 months were classified as middle income, while households with sufficient food and other goods, including consumer goods, for 12 months or more were categorized as rich.

\section{Statistical Analysis}

Logistic regression analysis was performed to identify the strength of the associations between the independent variables and the outcome of the study. First, the selected independent variables were included in the model individually to examine their univariate relationships with the outcome. Then, variables that were significant in the univariate analysis were included in the multiple logistic regression models. Next, multivariate logistic regression models were constructed to identify significant associations. Adjusted odds ratios (aORs), 
Table 1. Factors associated with stillbirth

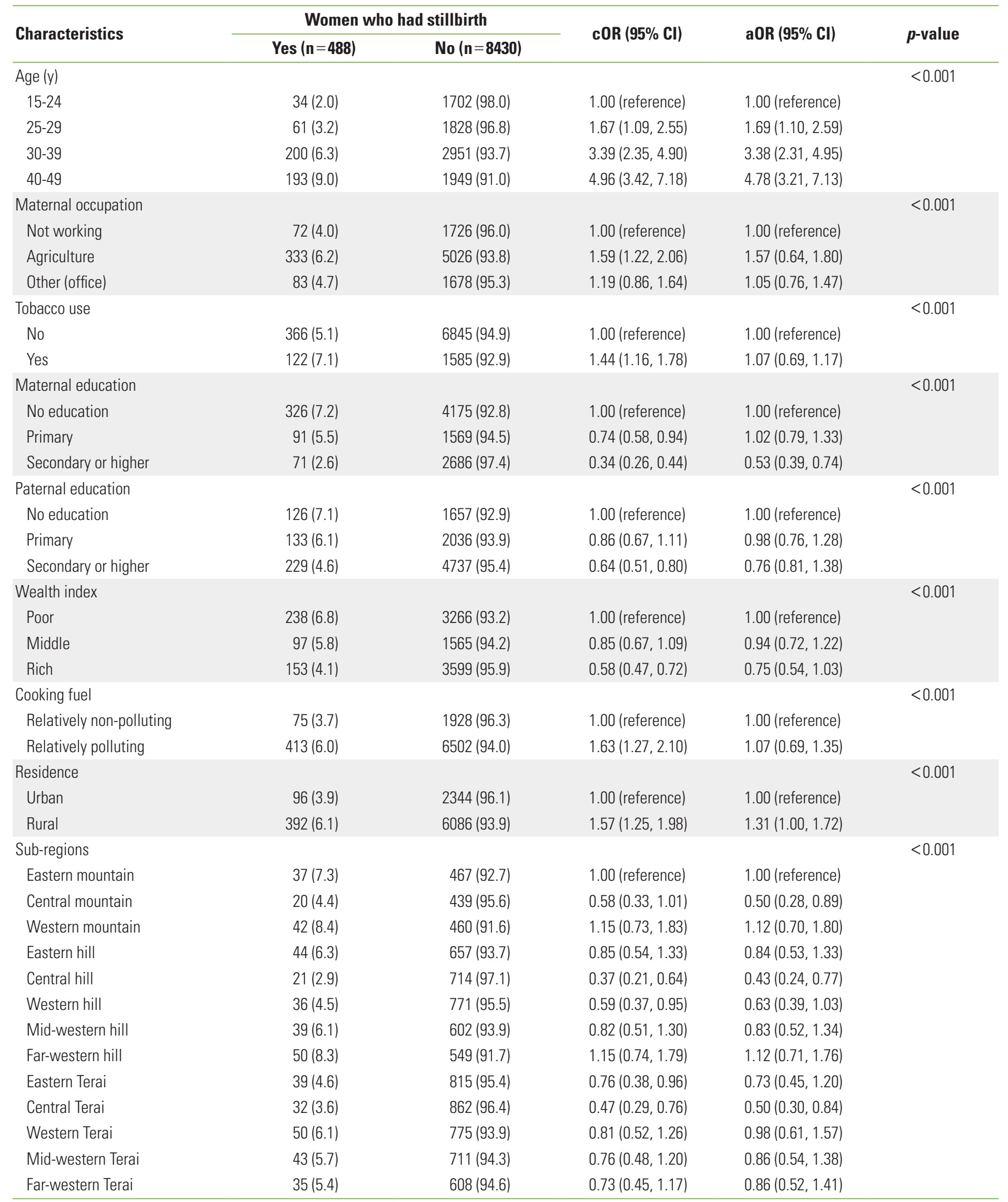

Values are presented as number (\%).

cOR, crude odds ratio; $\mathrm{Cl}$, confidence interval; aOR, adjusted odds ratio. 
together with $95 \%$ confidence intervals $(\mathrm{Cls})$, were used to quantify the independent relationships between the independent and dependent variables. Furthermore, the strength of the model was formulated the logit of the probability $p$-value that a woman had at least 1 stillbirth during her lifetime as an additive linear function of predictors, as follows:

$$
\ln \left(\frac{P}{1-P}\right)=\alpha+\sum_{i=1}^{k} \beta_{i} x_{i}
$$

In this model, $P$ is the expected probability, $\alpha$ is the intercept, $x_{i}$ through $x_{k}$ are variables, and $\beta_{i}$ through $\beta_{k}$ are regression coefficients. This model also provides $95 \% \mathrm{Cls}$ for the outcome for each risk factor adjusted for other risk factors using the sum contrasts method [15]. The $95 \% \mathrm{Cls}$ based on sum contrasts have the advantage of providing a simple criterion for classifying levels of the factor into 3 groups according to whether each corresponding $95 \% \mathrm{Cl}$ exceeds, crosses, or is below the overall percent of the specified causal group in each category compared with the overall percent. All statistical analyses were carried out using the R version 3.5.1 (https:// cran.r-project.org/bin/windows/base/old/3.5.1/). The $p$-values $<0.05$ were considered to indicate statistical significance.

\section{RESULTS}

Among 8918 ever-pregnant women aged 15-49 years, 488 had experienced at least 1 stillbirth during their lifetime. Table 1 shows the factors associated with stillbirth among ever-pregnant women in Nepal. Approximately $5.5 \%$ of total women had experienced a stillbirth, and stillbirth was associated with advanced age, maternal occupation, tobacco use, maternal education, parental education, economic status of the family, cooking fuel, residency, and region of residency. Women aged 4049 years ( $\mathrm{aOR}, 4.78 ; 95 \% \mathrm{Cl}, 3.21$ to 7.13 ) had a higher chance of stillbirth. Furthermore, women who worked in an office were less likely to experience stillbirth (aOR, $1.05 ; 95 \% \mathrm{Cl}, 0.76$ to 1.47 ) than those who worked in agriculture $(\mathrm{aOR}, 1.57 ; 95 \% \mathrm{Cl}, 0.64$ to 1.80). Similarly, maternal education was also associated with stillbirth. Women who had attained a secondary or higher level of education ( $\mathrm{aOR}, 0.53 ; 95 \% \mathrm{Cl}, 0.39$ to 0.74$)$ had a lower chance of stillbirth than those with a primary level of education (aOR, $1.02 ; 95 \% \mathrm{Cl}, 0.79$ to 1.33$)$. Moreover, women who used relatively polluting cooking fuels had a higher risk of stillbirth (aOR, $1.07 ; 95 \% \mathrm{Cl}, 0.69$ to 1.35$)$ than their counterparts. Women who lived in rural areas of Nepal had a higher chance of still-

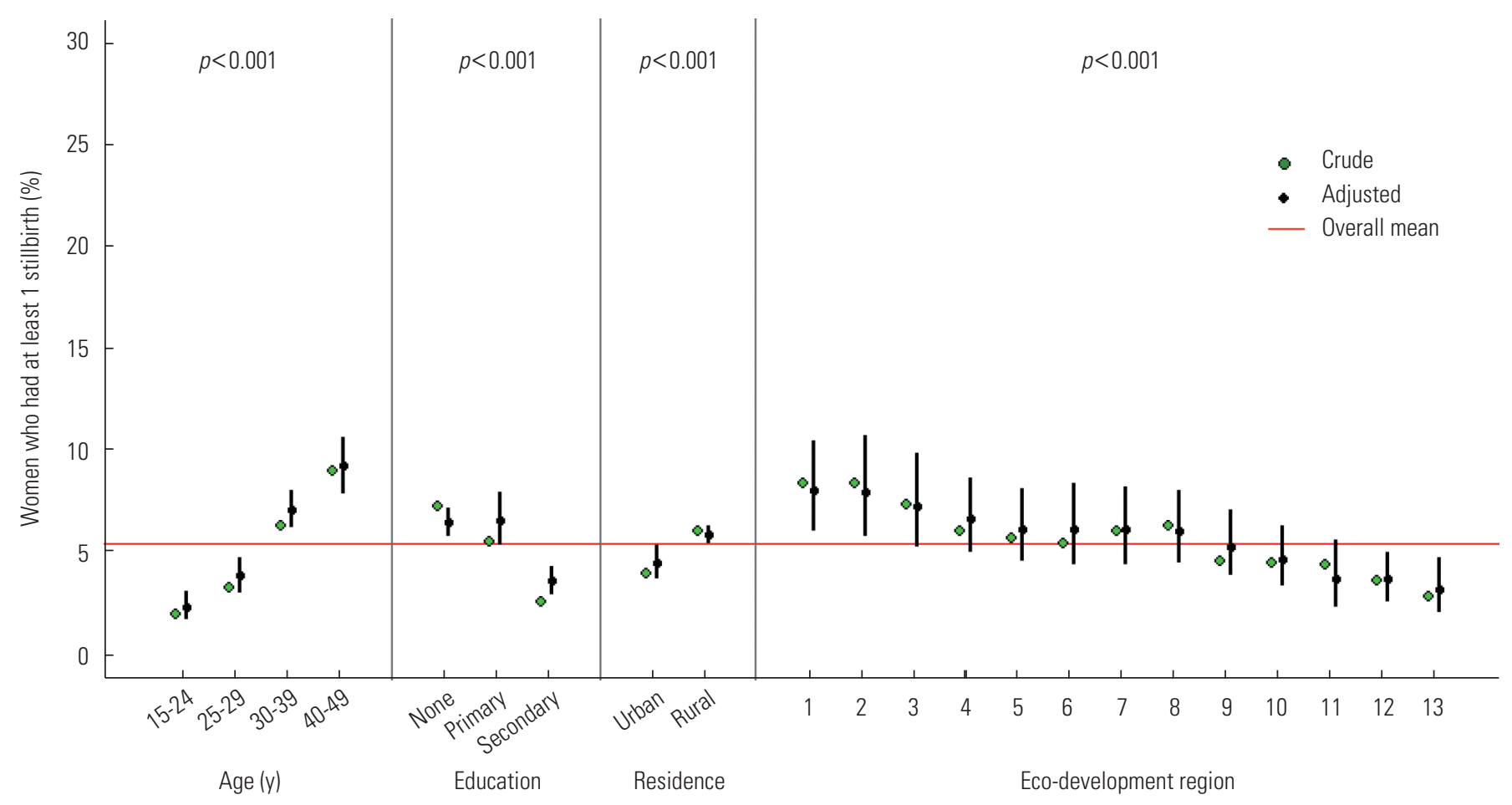

Figure 1. Crude and adjusted percent with 95\% confidence intervals of the women who had at least 1 stillbirth during their lifetime. 1: far western hill; 2: western mountain; 3: eastern mountain; 4: western Terai; 5: mid-western Terai; 6: far-western Terai; 7: mid-western hill; 8: eastern hill; 9: eastern Terai; 10: western hill; 11: central mountain; 12: central Terai; 13: central hill. 
birth (aOR, 1.31; $95 \% \mathrm{Cl}, 1.00$ to 1.72 ) than those who lived in urban areas. Likewise, women who were from the western mountain region (aOR, 1.12; $95 \% \mathrm{Cl}, 0.70$ to 1.80 ) and the farwestern hill region (aOR, 1.12; $95 \% \mathrm{Cl}, 0.71$ to 1.76 ) had a higher chance of stillbirth. All variables were significantly associated with stillbirth $(p<0.001)$. The proportion of women who had experienced stillbirth was highest in the age group of 40-49 years (9.0\%), followed by $30-39$ years (6.3\%). Stillbirth was most common among those working in the agriculture sector (6.2\%), and roughly $7 \%$ of tobacco users had experienced stillbirth. A history of stillbirth was highest among women with no formal education (7.2\%). Similarly, the proportion of women who had experienced stillbirth was highest among those whose husbands had no formal education (7.1\%). In terms of the wealth index, stillbirth was found to be most common in women belonging to the poor class (6.8\%). Furthermore, $6.0 \%$ of the women who used relatively polluting cooking fuels, such as kerosene and wood, had a history of stillbirth. The occurrence of stillbirth was found to be high among women residing in rural areas (6.1\%). Of the 13 sub-regions, women who lived in the western mountain, far-western hill, and eastern mountain districts had stillbirth rates of $8.4 \%, 8.3 \%$, and $7.3 \%$, respectively.

Figure 1 shows crude and adjusted percentages, with 95\% $\mathrm{Cls}$, of women who had at least 1 stillbirth during their lifetime. Furthermore, the figure shows results from fitting the logistic model for women who had at least 1 stillbirth, using age, education, place of residence, and sub-region as predictors. The risk of having experienced stillbirth increased with maternal age, and the proportion of women who had experienced miscarriage was highest among those aged 40 years and above. Similarly, the risk of stillbirth was found to be highest in women who were illiterate. Furthermore, residing in rural areas was found to be related to stillbirth. As shown in Figure 1, women living in rural areas were more likely to have experienced stillbirth than those living in urban areas. In the context of the 13 sub-regions, women from the far-western hill and western mountain regions had a significantly higher percentage of stillbirths. However, the central mountain, central hill, and central Terai (flatland) sub-regions had significantly lower stillbirth rates.

\section{DISCUSSION}

This study revealed that maternal age, place of residence, maternal education, and sub-region of residence were signifi- cantly related to the likelihood of having experienced stillbirth in Nepal. Stillbirth was found to be more common among older women. Our findings are consistent with those of several studies conducted in various countries; namely, increased maternal age is a significant risk factor for stillbirth $[13,16]$. This study showed that the risk of stillbirth was higher among women above 40 years and lower among those aged 15-24 years. This may have been because older women have had more pregnancies, each with a risk of stillbirth. Residing in rural areas has been found to be a factor significantly associated with stillbirth, and this finding is supported by a previous study conducted in Nepal [5]. The majority of the rural areas of Nepal had a high level of illiteracy, lack of health awareness, low socioeconomic status, insufficient transportation facilities, insufficient accessibility of health facilities, a lack of health service utilization, and a lack of trained health personnel. Therefore, women from these areas are more likely to experience stillbirth $[17,18]$.

Uneducated women or those with only primary education were more likely to have experienced a stillbirth than educated women. Our finding agrees with those of a study conducted in Canada and studies conducted in developing countries that found a significant association between stillbirth and maternal education at all gestational ages $[19,20]$. This association may exist because educated mothers are more conscious about maternal health, the importance of a balanced diet, and the need for ANC visits, and may be more likely to be aware of unhealthy behaviors like smoking and alcohol drinking. Out of the 13 subregions, women from the far-western hill and western mountain regions were significantly more likely to have experienced stillbirth than women from the central mountain, central hill, and central Terai regions. The difficult terrain, lack of transportation and road infrastructure facilities, and lack of health service facilities, as well as the poor economy and scarcity of food for long periods are responsible for stillbirths among women in these regions $[21,22]$. The husband's involvement is an essential factor during pregnancy, birth preparedness, and delivery at a health facility [23]. However, most of the husbands from these areas are migrants to India looking for employment [24].

Cooking fuel has been related to stillbirth in many studies; for example, a study conducted in India reported that the risk of stillbirth was significantly higher among women who used firewood for cooking than among those who used LPG [25]. However, the present study did not find this factor to be sig- 
nificant in the multivariate analysis. The use of tobacco was not found to be significantly associated with stillbirth in the study. However, tobacco use has been found to be a relevant factor in developed and developing countries [26,27]. According a study conducted in northeast Tanzania [28], low paternal education was strongly associated with stillbirth. However, in this study, paternal education was not associated with stillbirth in the multivariate analysis.

Our study had a few limitations. Firstly, we used secondary data, so it was not possible to evaluate other factors associated with stillbirth. Secondly, there is a chance of some response bias, as participants may have been vulnerable to recall bias and social desirability bias.

This study demonstrated that the major factors associated with women having experienced stillbirth in Nepal include increased maternal age, residing in rural areas, lack of maternal education, and living in the western mountain and the farwestern hill regions. Stillbirth remains a major public health problem in Nepal. To minimize stillbirth in Nepal, plans and policies should be focused on women with low education and mothers living in rural areas, with a special emphasis on women residing in the western mountain and far-western hill regions.

\section{CONFLICT OF INTEREST}

The authors have no conflicts of interest associated with the material presented in this paper.

\section{ACKNOWLEDGEMENTS}

The authors are grateful to Emeritus Professor Don McNeil for providing guidance and his valuable suggestions and to the Demographic and Health Survey team for granting us permission to use their data.

\section{ORCID}

Mahesh Bhusal https://orcid.org/0000-0003-2724-5334

Nirmal Gautam https://orcid.org/0000-0002-1375-3998

Apiradee Lim https://orcid.org/0000-0002-7137-4101

Phattrawan Tongkumchum https://orcid.org/0000-0001-

6166-2129

\section{REFERENCES}

1. Cousens S, Blencowe H, Stanton C, Chou D, Ahmed S, Steinhardt L, et al. National, regional, and worldwide estimates of stillbirth rates in 2009 with trends since 1995: a systematic analysis. Lancet 2011;377(9774):1319-1330.

2. McClure EM, Pasha O, Goudar SS, Chomba E, Garces A, Tshefu $A$, et al. Epidemiology of stillbirth in low-middle income countries: a Global Network Study. Acta Obstet Gynecol Scand 2011; 90(12):1379-1385.

3. United Nations Children's Fund. Maternal and newborn health disparities: Nepal; 2017 [cited 2018 Apr 29]. Available from: https://data.unicef.org/wp-content/uploads/country_profiles/Nepal/country\%20profile_NPL.pdf.

4. Lee AC, Mullany LC, Tielsch JM, Katz J, Khatry SK, Leclerq SC, et al. Community-based stillbirth rates and risk factors in rural Sarlahi, Nepal. Int J Gynaecol Obstet 2011;113(3):199-204.

5. Flenady V, Koopmans L, Middleton P, Frøen JF, Smith GC, Gibbons $\mathrm{K}$, et al. Major risk factors for stillbirth in high-income countries: a systematic review and meta-analysis. Lancet 2011; 377(9774):1331-1340.

6. Aminu M, Unkels R, Mdegela M, Utz B, Adaji S, van den Broek N. Causes of and factors associated with stillbirth in low- and middle-income countries: a systematic literature review. BJOG 2014;121 Suppl 4:141-153.

7. Lawn JE, Blencowe H, Pattinson R, Cousens S, Kumar R, Ibiebele I, et al. Stillbirths: Where? When? Why? How to make the data count? Lancet 2011;377(9775):1448-1463.

8. Vogel JP, Torloni MR, Seuc A, Betrán AP, Widmer M, Souza JP, et al. Maternal and perinatal outcomes of twin pregnancy in 23 low- and middle-income countries. PLoS One 2013;8(8):e70549.

9. Goldenberg RL, McClure EM, Bhutta ZA, Belizán JM, Reddy UM, Rubens CE, et al. Stillbirths: the vision for 2020. Lancet 2011; 377(9779):1798-1805.

10. Turton P, Evans C, Hughes P. Long-term psychosocial sequelae of stillbirth: phase Il of a nested case-control cohort study. Arch Womens Ment Health 2009;12(1):35-41.

11. Lamont K, Scott NW, Jones GT, Bhattacharya S. Risk of recurrent stillbirth: systematic review and meta-analysis. BMJ 2015; 350:h3080.

12. World Health Organization. Every newborn: an action plan to end preventable deaths; 2014 [cited 2018 Apr 18]. Available from: https://www.who.int/maternal_child_adolescent/documents/every-newborn-action-plan/en/.

13. K C A, Nelin V, Wrammert J, Ewald U, Vitrakoti R, Baral GN, et 
al. Risk factors for antepartum stillbirth: a case-control study in Nepal. BMC Pregnancy Childbirth 2015;15:146.

14. Ministry of Health, Nepal; New ERA; ICF. Nepal Demographic and Health Survey 2016; 2017 [cited 2018 Jun 21]. Available from: https://www.dhsprogram.com/pubs/pdf/fr336/fr336. pdf.

15. Tongkumchum P, McNeil D. Confidence intervals using contrasts for regression model. Songklanakarin J Sci Technol 2009; 31(2):151-156.

16. Asiki G, Baisley K, Newton R, Marions L, Seeley J, Kamali A, et al. Adverse pregnancy outcomes in rural Uganda (1996-2013): trends and associated factors from serial cross sectional surveys. BMC Pregnancy Childbirth 2015;15:279.

17. Sharma SR, Poudyal AK, Devkota BM, Singh S. Factors associated with place of delivery in rural Nepal. BMC Public Health 2014;14:306.

18. Lama S, Krishna AK. Barriers in utilization of maternal health care services: perceptions of rural women in Eastern Nepal. Kathmandu Univ Med J (KUMJ) 2014;12(48):253-258.

19. Auger N, Delézire P, Harper S, Platt RW. Maternal education and stillbirth: estimating gestational-age-specific and causespecific associations. Epidemiology 2012;23(2):247-254.

20. McClure EM, Saleem S, Goudar SS, Moore JL, Garces A, Esamai $F$, et al. Stillbirth rates in low-middle income countries 20102013: a population-based, multi-country study from the Global Network. Reprod Health 2015;12 Suppl 2:S7.

21. Bishnu Raj Upreti BR, Müller-Böker U. Livelihood insecurity and social conflict in Nepal; 2010 [cited 2018 Jun 21]. Available from: http://www.dsgz.geo.uzh.ch/pdfs/Upreti_Livelihoods.pdf.

22. Choulagai B, Onta S, Subedi N, Mehata S, Bhandari GP, Poudyal $A$, et al. Barriers to using skilled birth attendants' services in mid- and far-western Nepal: a cross-sectional study. BMC Int Health Hum Rights 2013;13:49.

23. Thapa DK, Niehof A. Women's autonomy and husbands' involvement in maternal health care in Nepal. Soc Sci Med 2013; 93:1-10.

24. Nepal B. Population mobility and spread of HIV across the Indo-Nepal border. J Health Popul Nutr 2007;25(3):267-277.

25. Lakshmi PV, Virdi NK, Sharma A, Tripathy JP, Smith KR, Bates $M N$, et al. Household air pollution and stillbirths in India: analysis of the DLHS-II National Survey. Environ Res 2013;121:1722.

26. Marufu TC, Ahankari A, Coleman T, Lewis S. Maternal smoking and the risk of still birth: systematic review and meta-analysis. BMC Public Health 2015;15:239.

27. Gupta PC, Subramoney S. Smokeless tobacco use and risk of stillbirth: a cohort study in Mumbai, India. Epidemiology 2006; 17(1):47-51.

28. Habib NA, Lie RT, Oneko O, Shao J, Bergsjø P, Daltveit AK. Sociodemographic characteristics and perinatal mortality among singletons in North East Tanzania: a registry-based study. J Epidemiol Community Health 2008;62(11):960-965. 